\title{
Effects of methanol and formic acid on human platelet aggregation
}

\author{
Mikio Marumo and Ichiro Wakabayashi
}

\begin{abstract}
Background: Although ethanol is known to inhibit platelet aggregation, the effects of another variant of alcohol, methanol, have not been reported. The purpose of this study was to determine whether methanol and its metabolite, formic acid, affect $\mathrm{Ca}^{2+}$ entry into and subsequent aggregation of platelets in vitro.

Methods: $\mathrm{Ca}^{2+}$ entry into and aggregation of human platelets were measured by spectrofluorometry using Fura-2/AM as an indicator and the light transmission method, respectively.

Results: Thrombin-induced platelet aggregation was significantly augmented by methanol at pharmacological concentrations (0.5-2\%) in a concentration-dependent manner. Methanol at $2 \%$ significantly attenuated thapsigargin-induced platelet aggregation, which was not significantly affected by lower concentrations ( 0.5 and 1\%) of methanol. Methanol (0.5-2\%) did not significantly affect platelet aggregation induced by 1-oleoyl-2-acetylsn-glycerol $(\mathrm{OAG})$, or $\mathrm{Ca}^{2+}$ entry into platelets induced by thrombin, thapsigargin, or OAG. Platelet aggregation induced by thrombin, thapsigargin, or OAG was significantly inhibited by formic acid at toxic concentrations ( $0.01 \%$ or higher). $\mathrm{Ca}^{2+}$ entry into platelets induced by thrombin or thapsigargin was also significantly inhibited by formic acid at $0.01 \%$ or higher, while that induced by OAG was not affected by formic acid at 0.005 and $0.01 \%$ and augmented by that at $0.02 \%$.

Conclusions: Methanol at pharmacological doses has diverse effects on platelet aggregation, depending on the aggregation stimuli, without affecting $\mathrm{Ca}^{2+}$ entry into platelets. Formic acid at toxic concentrations has an inhibitory action on platelets aggregation, which was partly explained by the reduction of $\mathrm{Ca}^{2+}$ entry into platelets.
\end{abstract}

Keywords: $\mathrm{Ca}^{2+}$ channels, Capacitative $\mathrm{Ca}^{2+}$ entry, Ethanol, Formic acid, Methanol, Platelet aggregation

\section{Background}

Alcohol drinking is known to have diverse effects on the risk of cardiovascular disease that depend on the amount of ethanol consumed; the risk is reduced by moderate drinking but is increased by excessive drinking $[1,2]$. The mechanism of the former beneficial effect is explained primarily by ethanol-induced increases in blood HDL cholesterol levels [3]. Attenuation of blood coagulability by drinking also lowers cardiovascular risk. Inhibition of platelet aggregation by ethanol $[4,5]$ is known to underlie the decreased blood coagulability in drinkers compared with nondrinkers, as is the decrease in blood levels of coagulation factors, including fibrinogen, in drinkers [6].

\footnotetext{
* Correspondence: wakabaya@hyo-med.ac.jp

Department of Environmental and Preventive Medicine, Hyogo College of

Medicine, Mukogawa-cho 1-1, Nishinomiya, Hyogo 663-8501, Japan
}

Methanol, another variant of alcohol, is used often in industry and is known to cause optic nerve injury and metabolic acidosis through the production of formic acid in vivo [7]. However, to the best of our knowledge, there have been no reports on effects of methanol and its metabolite, formic acid, on platelet function. Brain hemorrhage has been observed in $13.5 \%$ of patients with methanol intoxication [8]. Thus, there is a possibility of blood coagulation disorder caused by methanol intoxication.

Transplasmalemmal $\mathrm{Ca}^{2+}$ entry is a crucial step in the platelet activation process [9]. Our previous study demonstrated the diverse effects of ethanol on transplasmalemmal $\mathrm{Ca}^{2+}$ entry into the platelets through various pathways [10]. The purpose of the present study was to determine whether and how methanol and formic acid affect $\mathrm{Ca}^{2+}$ entry into and subsequent aggregation of 
platelets following different stimuli. For this purpose, we used three known platelet stimulants: thrombin, thapsigargin, and 1-oleoyl-2-acetyl-sn-glycerol (OAG).

\section{Methods}

\section{Preparation of washed platelet suspension}

Blood was obtained from healthy donors who had been medication-free for at least 10 days prior to the experiments. This study was approved by the Ethics Committee of Hyogo College of Medicine (No. 1799), and the experimental procedures were in accordance with the Helsinki Declaration. Blood $(18 \mathrm{ml})$ was rapidly transferred to a plastic tube containing $2 \mathrm{ml}$ of $3.2 \%$ sodium citrate and mixed. The blood was then centrifuged at $150 \times g$ for $10 \mathrm{~min}$, and the supernatant was obtained as a plateletrich plasma (PRP). PRP was subsequently mixed with $40 \mathrm{ml}$ of $\mathrm{Ca}^{2+}$ - and $\mathrm{Mg}^{2+}$-free Tyrode solution buffered by Hepes $(\mathrm{NaCl} 150 \mathrm{mM}, \mathrm{KCl} 5 \mathrm{mM}$, glucose $10 \mathrm{mM}$, HEPES $10 \mathrm{mM}$ ) (pH 7.4) and containing $1 \mathrm{mM}$ EGTA, and the mixture was centrifuged at $150 \times g$ for $10 \mathrm{~min}$. After the supernatant was further centrifuged at $400 \times g$ for $5 \mathrm{~min}$, the obtained pellet was suspended with $40 \mathrm{ml}$ of the above Tyrode-Hepes solution and then further centrifuged at $400 \times g$ for $5 \mathrm{~min}$. The pellet was suspended with $2 \mathrm{ml}$ of $\mathrm{Ca}^{2+}$-free Tyrode solution $(\mathrm{NaCl} 150 \mathrm{mM}$, $\mathrm{KCl} 5 \mathrm{mM}, \mathrm{MgCl}_{2} 1 \mathrm{mM}$, glucose $10 \mathrm{mM}$, and HEPES $10 \mathrm{mM}$ ) ( $\mathrm{pH} 7.4)$, and the resulting platelet suspension was used for the experiments within $2 \mathrm{~h}$ after blood collection. The concentration of platelets in its suspension used for each experiment was adjusted to be approximately $10^{5} / \mu \mathrm{l}$.

\section{Measurement of $\left[\mathrm{Ca}^{2+}\right]_{\mathrm{i}}$}

$\left[\mathrm{Ca}^{2+}\right]_{\mathrm{i}}$ was ascertained using the fluorescent $\mathrm{Ca}^{2+}$ indicator Fura-2. Fura-2 is a ratiometric fluorescent indicator dye that binds to free intracellular calcium. Fura-2-acetoxymethyl ester (Fura-2/AM) is a membranepermeant derivative of Fura-2 and is often used for measuring intracellular calcium. The washed platelets were loaded with Fura-2/AM (final concentration, $5 \mu \mathrm{M}$ ) at $37{ }^{\circ} \mathrm{C}$ for $30 \mathrm{~min}$. After loading, the platelets were washed once with $\mathrm{Ca}^{2+}$ - and $\mathrm{Mg}^{2+}$-free Tyrode solution buffered by Hepes $(\mathrm{NaCl} 150 \mathrm{mM}, \mathrm{KCl} 5 \mathrm{mM}$, glucose $10 \mathrm{mM}$, HEPES $10 \mathrm{mM}$ ) (pH 7.4) containing $1 \mathrm{mM}$ EGTA, and they were resuspended in $2 \mathrm{ml}$ of a $\mathrm{Ca}^{2+}$-free Tyrode solution buffered by Hepes ( $\mathrm{NaCl} 150 \mathrm{mM}, \mathrm{KCl} 5 \mathrm{mM}, \mathrm{MgCl}_{2} 1 \mathrm{mM}$, glucose $10 \mathrm{mM}$, and HEPES $10 \mathrm{mM}$ ) (pH 7.4) (nominally $\mathrm{Ca}^{2+}$-free solution).

Fluorescence measurements were carried out with a dual-wavelength spectrofluorimeter (F-2500 Fluorescence Spectrophotometer, Hitachi High-Technologies Corporation, Tokyo, Japan) using a 0.4-ml cuvette maintained at $37{ }^{\circ} \mathrm{C}$. The wavelengths used for excitation were 340 and $380 \mathrm{~nm}$, and the wavelength used for emission was
$510 \mathrm{~nm}$. The fractional changes in $\left[\mathrm{Ca}^{2+}\right]_{i}$ were determined using a ratio (R) of fluorescence intensity $(F)$ of F340/F380. The fluorescence after sequential addition of $0.25 \%$ Triton X-100 and EGTA (5 mM) to the platelet suspension provided the maximum fluorescence ratio (Rmax) and minimum fluorescence ratio (Rmin), respectively. $\left[\mathrm{Ca}^{2+}\right]_{\mathrm{i}}$ was calculated using the following formula [11]:

$$
\left[\mathrm{Ca}^{2+}\right]_{\mathrm{i}}=(R-\mathrm{Rmin}) /(\mathrm{Rmax}-R) \times \beta \times \mathrm{Kd},
$$

where $\beta$ is the ratio of the emission fluorescence values at $380-\mathrm{nm}$ excitation in the presence of Triton X-100 and EGTA and $\mathrm{Kd}$; the dissociation constant for $\mathrm{Ca}^{2+}$ is 224. $\mathrm{Ca}^{2+}$ entry induced by thrombin, thapsigargin, or OAG was expressed as the net increase in $\left[\mathrm{Ca}^{2+}\right]_{i}$ calculated by subtraction of the basal $\left[\mathrm{Ca}^{2+}\right]_{\mathrm{i}}$ level from the maximum $\left[\mathrm{Ca}^{2+}\right]_{\mathrm{i}}$ level after stimulation.

\section{Measurement of platelet aggregation}

Platelet aggregation was measured using platelets suspended in $\mathrm{Ca}^{2+}$-free Tyrode solution buffered by Hepes $\left(\mathrm{NaCl} 150 \mathrm{mM}, \mathrm{KCl} 5 \mathrm{mM}, \mathrm{MgCl}_{2} 1 \mathrm{mM}\right.$, glucose $10 \mathrm{mM}$, and HEPES $10 \mathrm{mM})(\mathrm{pH}$ 7.4) and evaluated using an aggregometer (IMI PRP313M, TAIYO Instruments INC., Osaka, Japan) that measures increases in light transmission through a cuvette $(0.2 \mathrm{ml})$ containing stirred platelet suspension. The light transmission through a washed platelet suspension without any treatment and that through a suspended buffer not containing platelets were considered as 0 and $100 \%$, respectively. The percentage of aggregation during the course of each experiment was calculated. The experimental conditions were the same as those for $\left[\mathrm{Ca}^{2+}\right]_{\mathrm{i}}$ measurement except for the volume of the cuvettes.

\section{Protocols for experiments assessing $\mathrm{Ca}^{2+}$ entry and platelet aggregation}

Platelets were stabilized in a nominally $\mathrm{Ca}^{2+}$-free medium in the cuvette for $3 \mathrm{~min}$ and then stimulated with each stimulant (thrombin $[0.025 \mathrm{U} / \mathrm{ml}]$, thapsigargin $[1 \mu \mathrm{M}]$, or OAG $[100 \mu \mathrm{M}])$. At $1 \mathrm{~min}$ after the addition of each stimulant, the platelets were pretreated with methanol or formic acid at each concentration or a vehicle (distilled water) for $1 \mathrm{~min}$. Then, $\mathrm{Ca}^{2+}$ entry and aggregation were induced by adding $\mathrm{CaCl}_{2}(0.5 \mathrm{mM})$ to the cuvette. It is known that threshold limit value (TLV) for methanol in the industry is $200 \mathrm{ppm}$, and exposure to this concentration of methanol causes blood methanol concentration of about $10 \mathrm{mg} / \mathrm{L}(0.00126 \%)$ [12]. In previous studies on acute methanol intoxication, blood concentrations of methanol were reportedly $147.3 \mathrm{mg} / \mathrm{dl}$ [13] and $1.75 \mathrm{~g} / \mathrm{l}$ [14], which correspond to about 0.186 and $0.221 \%$, respectively. Thus, blood concentrations of methanol in its acute intoxication are expected to be 
about $0.2 \%$. Then, we first investigated the effects of these environmental and toxic concentrations of methanol $(0.001,0.02$, and $0.2 \%)$ on platelet function. Higher pharmacological concentrations of methanol (0.5-2\%) were also tested in further experiments. TLV of formic acid is known to be $5 \mathrm{ppm}$, and the blood concentrations of formic acid in patients with acute methanol poisoning who needed to be treated by dialysis therapy were reported to be $13.4 \mathrm{mg} / \mathrm{dl} \mathrm{[15]} \mathrm{or} 16.9 \mathrm{mg} / \mathrm{dl} \mathrm{[16],}$ which correspond to about 0.0110 and $0.0139 \%$, respectively. Then, we used concentrations of formic acid at $0.005-0.02 \%$ in this study.

\section{Drugs}

Methanol (chemical-grade quality, 99.8 wt\% purity) and formic acid (chemical-grade quality, $98.0 \mathrm{wt} \%$ purity) purchased from Wako Pure Chemical Co., Osaka, Japan, were prepared at the time of use and diluted with distilled water. Thapsigargin (Sigma, St Louis, Missouri, USA), OAG (Sigma), and Fura-2/AM (Dojindo Laboratories, Kumamoto, Japan) were dissolved in dimethylsulfoxide to make stock solutions of 1,100 , and $5 \mathrm{mM}$, respectively, and stored at $-80{ }^{\circ} \mathrm{C}$. Bovine thrombin (Wako Pure Chemical) was dissolved in distilled water to make a stock solution of $1 \mathrm{U} / \mu \mathrm{l}$ and was stored at $-80^{\circ} \mathrm{C}$.

\section{Statistical analysis}

The data are presented as means \pm standard deviations. Statistical analysis was performed using the analysis of variance (ANOVA) followed by Scheffé $F$ test. $p$ values less than 0.05 were regarded as significant.

\section{Results}

Effects of methanol at environmental and toxic concentrations on platelet aggregation and $\mathrm{Ca}^{2+}$ entry into platelets induced by different stimuli

Figure 1 shows the effects of methanol at 0.001, 0.02, and $0.2 \%$ on platelet aggregation (a) and $\mathrm{Ca}^{2+}$ entry into platelets (b) induced by thrombin. Methanol at these environmental and toxic concentrations significantly affected neither platelet aggregation nor $\mathrm{Ca}^{2+}$ entry into platelets. Platelet aggregation and $\mathrm{Ca}^{2+}$ entry into platelets induced by thapsigargin and OAG were also not significantly affected by methanol at $0.001,0.02$, and $0.2 \%$ (data not shown).

Effects of methanol at pharmacological concentrations on platelet aggregation induced by different stimuli

Figure 2 shows the effects of methanol at $0.5-2 \%$ on platelet aggregation induced by thrombin (a), thapsigargin (b), and OAG (c). Thrombin-induced aggregation was significantly increased by methanol in a concentration-dependent manner. On the other hand, methanol at a higher concentration (2\%) but not lower concentrations (0.5 and 1\%)

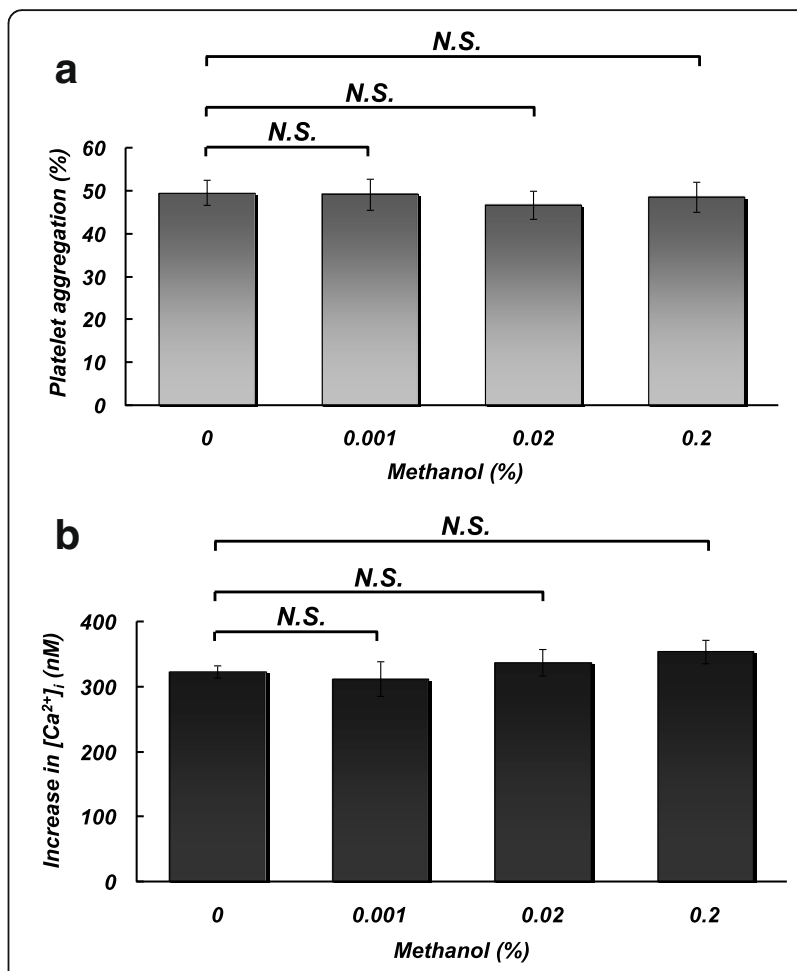

Fig. 1 Effects of pretreatment with different concentrations (0, 0.001, 0.02 , and $0.2 \%$ ) of methanol on platelet aggregation (at $5 \mathrm{~min}$ ) (a) and $\mathrm{Ca}^{2+}$ entry (b) induced by extracellular addition of $\mathrm{CaCl}_{2}$ $(0.5 \mathrm{mM})$ in the presence of thrombin $(0.025 \mathrm{U} / \mathrm{ml})$. N.S. no significant difference. $N=4$

significantly attenuated thapsigargin-induced aggregation. OAG-induced aggregation was not significantly affected by methanol at $0.5-2 \%$.

Effects of methanol at pharmacological concentrations on $\mathrm{Ca}^{2+}$ entry into platelets induced by different stimuli

Figure 3 shows the effects of methanol at $0.5-2 \%$ on $\mathrm{Ca}^{2}$ + entry into platelets corresponding to their aggregation induced by thrombin (a), thapsigargin (b), and OAG (c). Methanol at the above concentrations did not significantly affect $\mathrm{Ca}^{2+}$ entry into platelets induced by any of the three stimulants.

Effects of formic acid at toxic concentrations on platelet aggregation induced by different stimuli

Figure 4 shows the effects of formic acid at $0.005-0.02 \%$ on platelet aggregation induced by thrombin (a), thapsigargin (b), and OAG (c). Platelet aggregation induced by thrombin, thapsigargin, or OAG was significantly attenuated by formic acid at 0.01 and $0.02 \%$.

Effects of formic acid at toxic concentrations on $\mathrm{Ca}^{2+}$ entry into platelets induced by different stimuli Figure 5 shows the effects of formic acid at $0.005-0.02 \%$ on $\mathrm{Ca}^{2+}$ entry into platelets corresponding to their 


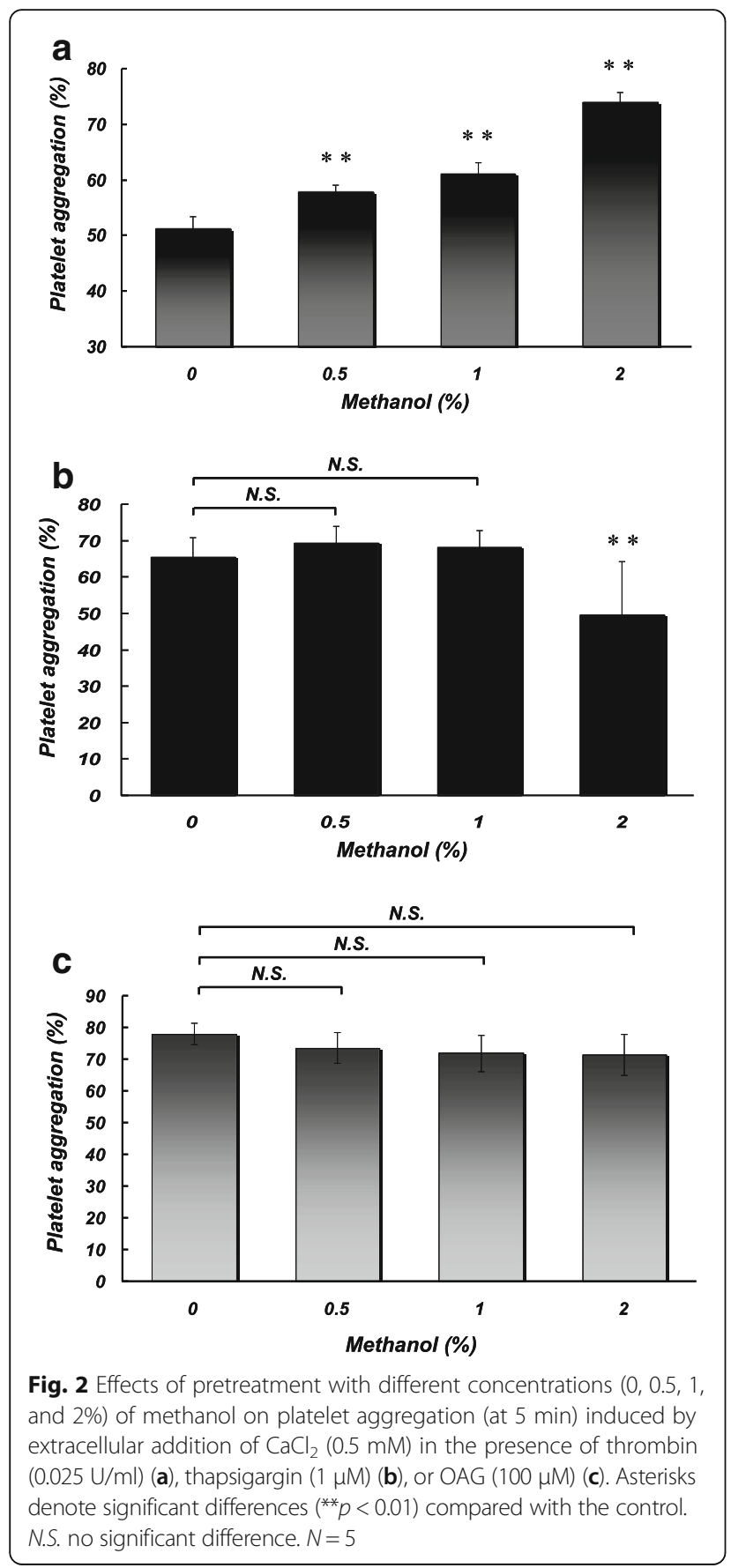

aggregation induced by thrombin (a), thapsigargin (b), and OAG (c). Formic acid at 0.01 and $0.02 \%$ significantly inhibited $\mathrm{Ca}^{2+}$ entry into platelets induced by thrombin and thapsigargin. Formic acid at 0.005\% also significantly reduced $\mathrm{Ca}^{2+}$ entry into platelets induced by thapsigargin. On the other hand, formic acid at a higher concentration of $0.02 \%$ but not at 0.005 and $0.01 \%$ significantly augmented $\mathrm{Ca}^{2+}$ entry into platelets induced by OAG.

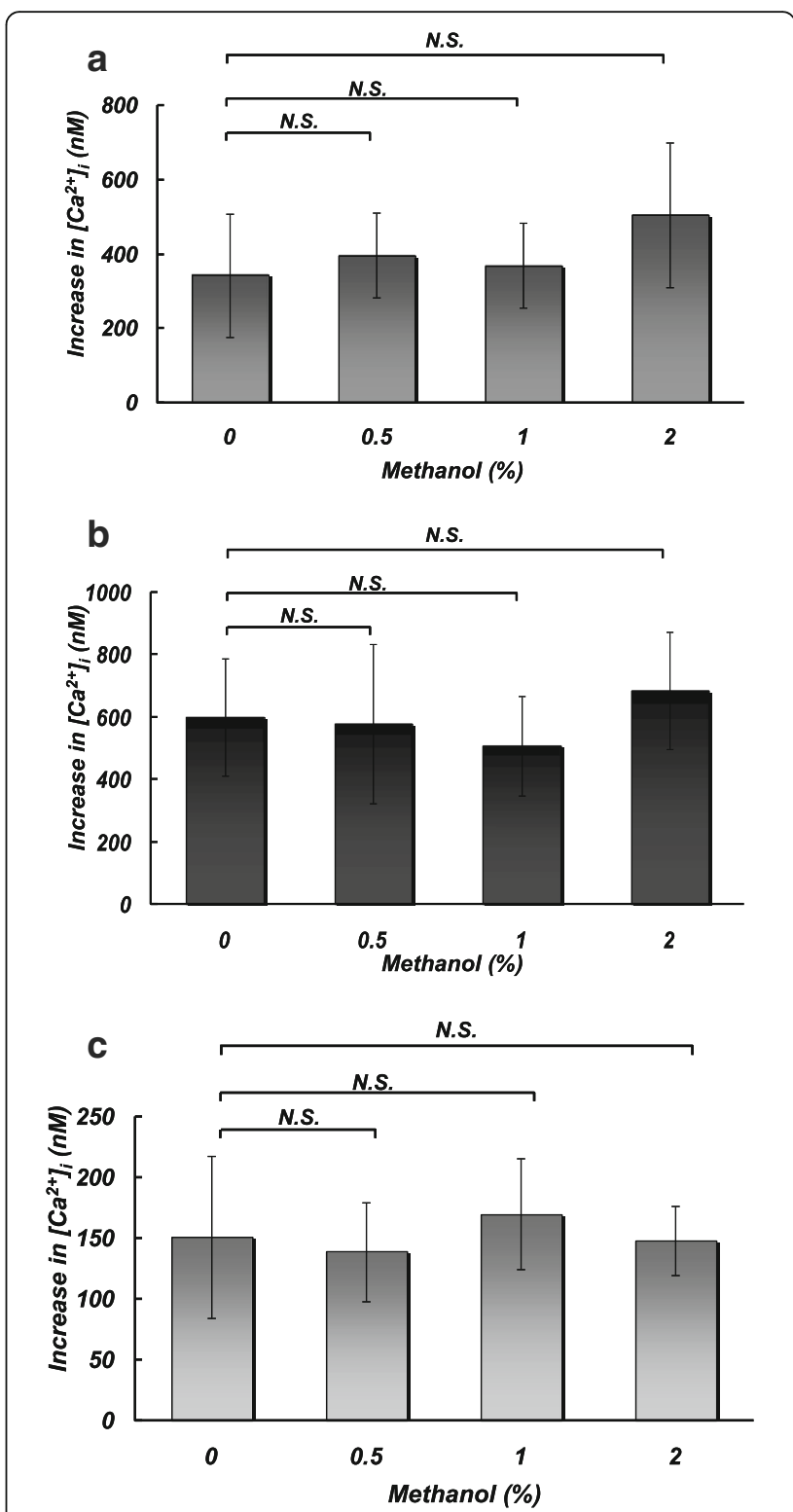

Fig. 3 Effects of pretreatment with different concentrations $(0,0.5,1$, and $2 \%)$ of methanol on $\mathrm{Ca}^{2+}$ entry induced by extracellular addition of $\mathrm{CaCl}_{2}(0.5 \mathrm{mM})$ in the presence of thrombin $(0.025 \mathrm{U} / \mathrm{ml})(\mathbf{a})$, thapsigargin $(1 \mu \mathrm{M})(\mathbf{b})$, or $\mathrm{OAG}(100 \mu \mathrm{M})(\mathbf{c})$. N.S. no significant difference. $N=6-8$

\section{Effects of formic acid on extraplatelet $\mathrm{pH}$}

Additions of formic acid at $0.005,0.01$, and $0.02 \%$ to the solution suspending platelets lowered its $\mathrm{pH}$ (means \pm standard deviations) from $7.424 \pm 0.005$ to $7.299 \pm$ $0.043(p<0.05), 7.017 \pm 0.013(p<0.01)$, and $6.234 \pm 0.085$ $(p<0.01)$, respectively.

\section{Discussion}

Although environmental and toxic concentrations of methanol did not affect platelet aggregation and $\mathrm{Ca}^{2+}$ entry into platelets, methanol at pharmacological doses 

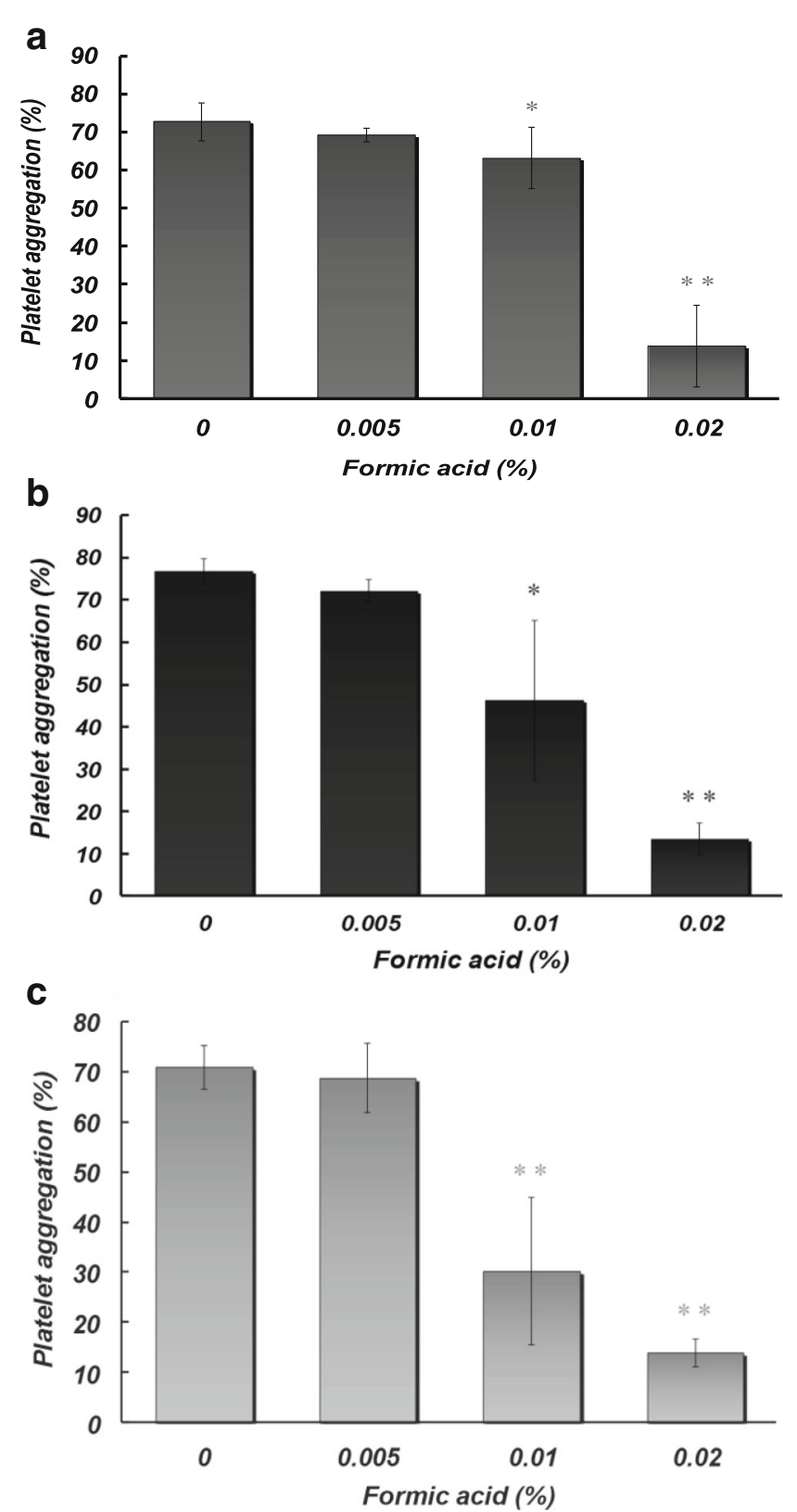

Fig. 4 Effects of pretreatment with different concentrations $(0,0.005,0.01$, and $0.02 \%)$ of formic acid on platelet aggregation (at 5 min) induced by extracellular addition of $\mathrm{CaCl}_{2}(0.5 \mathrm{mM})$ in the presence of thrombin $(0.025 \mathrm{U} / \mathrm{ml})(\mathbf{a})$, thapsigargin $(1 \mu \mathrm{M})(\mathbf{b})$, or OAG $(100 \mu \mathrm{M})(\mathbf{c})$. Asterisks denote significant differences $\left({ }^{*} p<0.05 ;{ }^{* *} p<0.01\right)$ compared with the control. $N=4-10$

showed diverse effects on platelet aggregation that depended on the aggregating stimulant. Thrombininduced aggregation was increased by methanol $(0.5-2 \%)$, while thapsigargin-induced aggregation was inhibited by a higher concentration $(2 \%)$ of methanol but was not significantly changed by lower concentrations. Platelet aggregation is known to depend strongly on $\mathrm{Ca}^{2+}$ entry [9], and thus we suspected that $\mathrm{Ca}^{2+}$ entry pathways would be affected by methanol. In this study, we used three platelet activating stimulants that act through different mechanisms. Thrombin activates its receptors, resulting in hydrolysis of phosphoinositides and subsequent production of two signal transduction messengers, inositol trisphosphate and diacylglycerol. The former induces mobilization of $\mathrm{Ca}^{2+}$ from its intracellular stores, which triggers transmembranous $\mathrm{Ca}^{2+}$ entry, so-called capacitative $\mathrm{Ca}^{2+}$ entry, through TRPC (transient receptor potential canonical) 1/4/5 channels [17]. The latter facilitates TRPC3/6/7 channel-mediated $\mathrm{Ca}^{2+}$ entry $[18,19]$. Thapsigargin and OAG were used as 


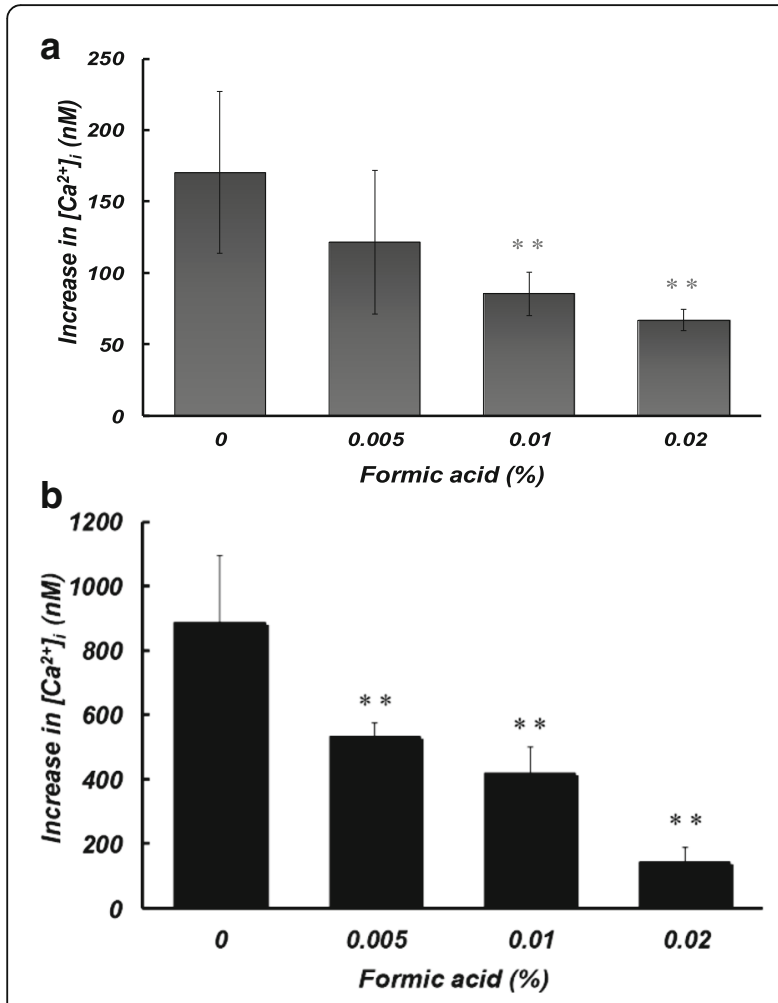

C

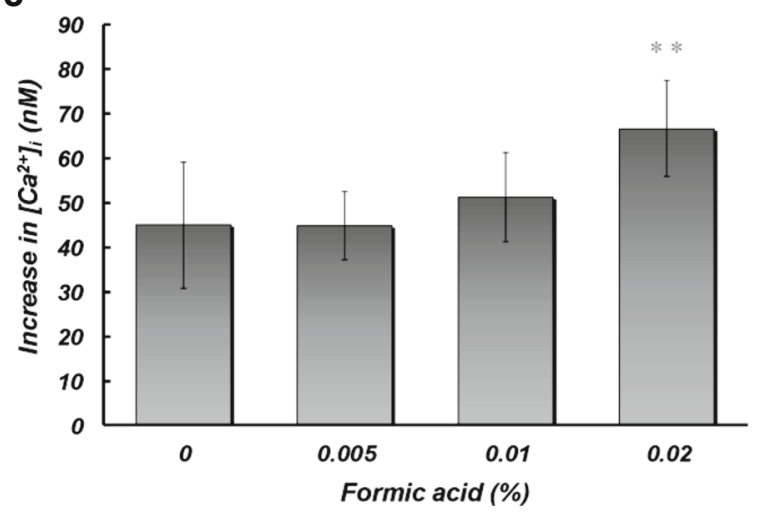

Fig. 5 Effects of pretreatment with different concentrations (0, $0.005,0.01$, and $0.02 \%$ ) of formic acid on $\mathrm{Ca}^{2+}$ entry induced by extracellular addition of $\mathrm{CaCl}_{2}(0.5 \mathrm{mM})$ in the presence of thrombin $(0.025 \mathrm{U} / \mathrm{ml})(\mathbf{a})$, thapsigargin $(1 \mu \mathrm{M})(\mathbf{b})$, or $\mathrm{OAG}$ $(100 \mu \mathrm{M})(\mathbf{c})$. Asterisks denote significant differences $\left({ }^{* *} p<0.01\right)$ compared with the control. $N=8-9$

mimics of inositol trisphosphate and diacylglycerol, respectively. However, methanol did not affect $\mathrm{Ca}^{2+}$ entry induced by any of the stimulants used in this study. Therefore, the effects of methanol on platelet aggregation are thought to be independent of $\mathrm{Ca}^{2+}$ entry, and methanol is suggested to affect signaling pathways in platelets that are downstream of the increase in intracellular $\mathrm{Ca}^{2+}$ concentrations. Further studies are needed to clarify the mechanisms for the diverse effects of methanol on platelet aggregation induced by thrombin and thapsigargin.

Blood concentrations of methanol in its acute intoxication have been reported to be about $0.2 \%$ [13, 14]. Thus, the concentrations of methanol that exerted significant actions on platelet aggregation in the present study were higher than those attained under an environmental condition and those observed in patients with acute methanol intoxication. Therefore, it is unlikely that methanol influences blood coagulability in vivo through its direct action on platelet aggregation even under a toxic condition.

On the other hand, formic acid, the final metabolite of methanol in vivo, at toxic concentrations showed inhibitory effects on platelet aggregation and corresponding $\mathrm{Ca}^{2+}$ entry in platelets in response to thrombin and thapsigargin. Therefore, formic acid inhibits platelet aggregation through attenuating capacitative $\mathrm{Ca}^{2+}$ entry. Since thrombin is a physiological agonist for platelet aggregation, there is a possibility that bleeding tendency due to attenuation of platelet aggregation occurs in patients with methanol poisoning, and further clinical studies are needed to test this hypothesis. Platelet aggregation induced by OAG was also attenuated in the presence of formic acid, while corresponding $\mathrm{Ca}^{2+}$ entry in platelets induced by OAG was not affected by formic acid at lower concentrations (0.005 and $0.01 \%)$ and was rather augmented by formic acid at a higher concentration $(0.02 \%)$. Thus, in addition to the inhibitory action on capacitative $\mathrm{Ca}^{2+}$ entry, there may be another inhibitory mechanism, besides action on $\mathrm{Ca}^{2+}$ entry, for formic acid-induced inhibition of platelet aggregation. This is the first study showing the inhibitory action of formic acid on $\mathrm{Ca}^{2+}$ entry into platelets and subsequent aggregation of them. Further studies are also needed to clarify the $\mathrm{Ca}^{2+}$ entry-independent pathway for platelet aggregation that is inhibited by formic acid.

The $\mathrm{pH}$ of the solution suspending platelets was lowered by the addition of formic acid (0.005-0.02\%) in a concentration-dependent manner. We previously reported that thapsigargin-induced $\mathrm{Ca}^{2+}$ entry into and subsequent aggregation of platelets were decreased under the condition of extracellular acidosis ( $\mathrm{pH}$ 6.9) and were increased under the condition of extracellular alkalosis ( $\mathrm{pH}$ 7.9) [20]. Thus, platelet aggregation induced by thapsigargin depends on extracellular $\mathrm{pH}$ in the range of $\mathrm{pH}$ from 6.9 to 7.9 . Interestingly, the degrees of inhibition of $\mathrm{Ca}^{2+}$ entry and subsequent aggregation by extracellular acidosis $(\mathrm{pH}$ 6.9) [20] were comparable to the degrees of inhibition by formic acid at $0.01 \%$ (Figs. 4 and 5), which caused a similar (slightly lower) degree of intracellular acidosis $(\mathrm{pH} 7.017 \pm 0.013)$ in the present study. Therefore, we concluded that formic acid-induced inhibition of $\mathrm{Ca}^{2+}$ entry and 
subsequent aggregation resulted mainly from extracellular acidosis induced by formic acid. This explanation is plausible because metabolic acidosis occurs in patients with severe methanol poisoning [21].

Table 1 compares the effects of methanol and ethanol on $\mathrm{Ca}^{2+}$ entry and subsequent platelet aggregation. In our previous study, ethanol at its toxic concentrations $(0.5-2 \%)$ inhibited platelet aggregation in a concentration-dependent manner irrespective of platelet stimuli [10]. The effects of ethanol on $\mathrm{Ca}^{2+}$ entry were complicated. Ethanol decreased $\mathrm{Ca}^{2+}$ entry induced by thapsigargin and increased that induced by OAG and did not significantly affect that induced by thrombin [10]. Thus, ethanol has diverse actions on $\mathrm{Ca}^{2+}$ entry mediated by TRPC1/4/5 and TRPC $3 / 6 / 7$ channels, and these actions were thought to be canceled when platelets were stimulated with thrombin, which activates both TRPC $1 / 4 / 5$ and TRPC $3 / 6 / 7$ channels. In addition to these actions on $\mathrm{Ca}^{2+}$ entry, ethanol has an inhibitory effect on platelet aggregation independent of $\mathrm{Ca}^{2+}$ entry. Thus, the effects of ethanol on $\mathrm{Ca}^{2+}$ entry into and aggregation of platelets are quite different from the effects of methanol reported in the present study. Figure 6 shows representative recordings of thrombin-induced platelet aggregation in the presence of the same concentration (2\%) of methanol and ethanol, which increased and decreased the aggregation, respectively. Since both methanol and ethanol are membrane-permeable, they are speculated to affect not only different types of $\mathrm{Ca}^{2+}$ channels in the plasmalemma but also various intracellular organelles. Further studies are needed to determine the reasons for the differing actions of methanol and ethanol on $\mathrm{Ca}^{2+}$ entry into and aggregation of platelets, and to clarify how these actions are related to the differences in the structures of these alcohol variants.

\section{Conclusion}

Methanol, at pharmacological doses $(0.5 \%$ or higher) but not at toxic doses, had diverse actions on platelet

Table 1 Comparison of effects of methanol and ethanol on aggregation of and $\mathrm{Ca}^{2+}$ influx into platelets induced by different stimulants

\begin{tabular}{lll}
\hline & Methanol & Ethanol \\
\hline Aggregation & $\uparrow$ & $\downarrow$ \\
Thrombin & $\rightarrow \downarrow$ & $\downarrow$ \\
Thapsigargin & $\rightarrow$ & $\downarrow$ \\
OAG & & \\
Ca influx & $\rightarrow$ & $\rightarrow$ \\
Thrombin & $\rightarrow$ & $\downarrow$ \\
Thapsigargin & $\rightarrow$ & $\uparrow$ \\
OAG & &
\end{tabular}

$\uparrow$ increase; $\downarrow$ decrease; $\rightarrow$ no change

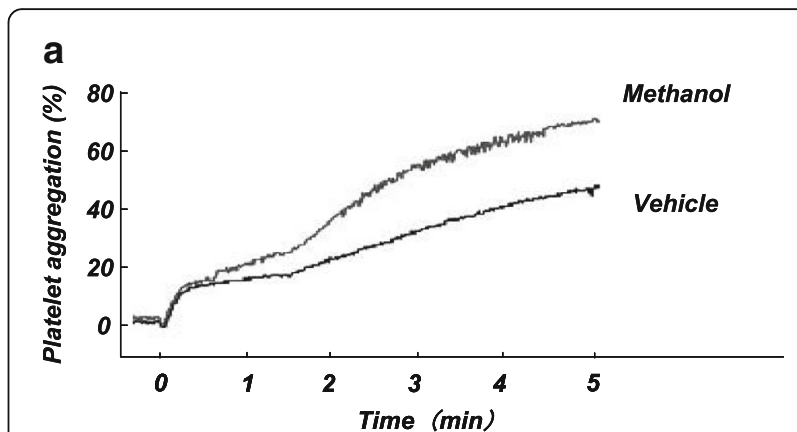

b

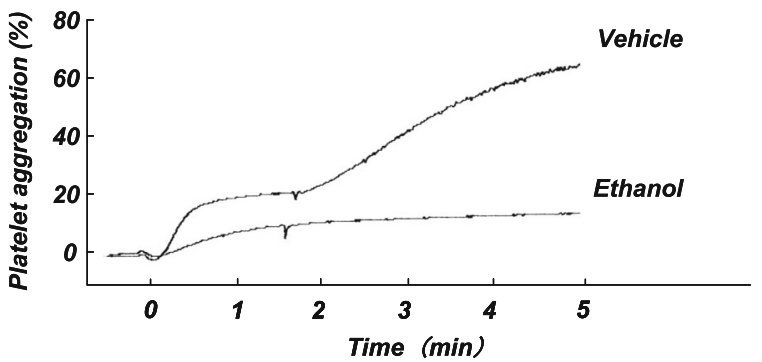

Fig. 6 Representative recordings of thrombin-induced platelet aggregation in the presence or absence of methanol (a) or ethanol (b). The effect of ethanol on platelet aggregation was examined by the same method as that used in the present study. Methanol (2\%), ethanol (2\%), or a vehicle was added to a platelet suspension in the nominally $\mathrm{Ca}^{2+}$-free solution. Platelets were stimulated with thrombin $(0.025 \mathrm{U} / \mathrm{ml})$, and platelet aggregation was induced by extracellular addition of $\mathrm{CaCl}_{2}(0.5 \mathrm{mM})$ at time 0 and was measured by the light transmission method as mentioned in the "Methods" section

aggregation-levels of aggregation induced by thrombin and thapsigargin were increased and decreased, respectively, by methanol. On the other hand, methanol showed no significant effects on $\mathrm{Ca}^{2+}$ entry in platelets. Thus, methanol has diverse effects on platelet aggregation, depending on the aggregation stimuli, without affecting $\mathrm{Ca}^{2+}$ entry into platelets. Formic acid at toxic doses ( $0.01 \%$ or higher) showed significant inhibitory actions on platelet aggregation and corresponding $\mathrm{Ca}^{2+}$ entry in platelets, which may be caused by extracellular acidosis. Therefore, it is suggested that, in methanol intoxication, platelet aggregation is not affected by methanol itself but is inhibited by its metabolite, formic acid, resulting in bleeding tendency, which may be involved in etiology of complicated brain hemorrhage [8].

\section{Abbreviations \\ ANOVA: Analysis of variance; Fura-2/AM: Fura-2-acetoxymethyl ester; OAG: 1-oleoyl-2-acetyl-sn-glycerol; PRP: Platelet-rich plasma; Rmax: Maximum fluorescence ratio; Rmin: Minimum fluorescence ratio; TLV: Threshold limit value; TRPC: Transient receptor potential canonical \\ Acknowledgments \\ The authors wish to express their gratitude to all the participants for their cooperation in this study.}




\section{Funding}

This work was supported by the Grant-in-Aid for researchers at Hyogo College of Medicine (2012)

\section{Availability of data and materials}

Please contact the authors for the data requests.

\section{Authors' contributions}

MM and IW prepared the design of this study. MM performed the experiments and analyzed the data, and IW wrote the manuscript. Both authors read and approved the final manuscript.

\section{Ethics approval and consent to participate}

This study protocol was approved by the Ethics Committee of Hyogo College of Medicine (approval number 1799). All study participants provided written informed consent.

\section{Consent for publication}

Not applicable.

\section{Competing interests}

The authors declare that they have no competing interests.

\section{Publisher's Note}

Springer Nature remains neutral with regard to jurisdictional claims in published maps and institutional affiliations.

Received: 19 September 2017 Accepted: 1 December 2017

Published online: 16 December 2017

\section{References}

1. Corrao G, Rubbiati L, Bagnardi V, Zambon A, Poikolainen K. Alcohol and coronary heart disease: a meta-analysis. Addiction. 2000;95:1505-23.

2. Mazzaglia G, Britton AR, Altmann DR, Chenet L. Exploring the relationship between alcohol consumption and non-fatal or fatal stroke: a systematic review. Addiction. 2001;96:1743-56.

3. Gaziano JM, Buring JE, Breslow JL, Goldhaber SZ, Rosner B, VanDenburgh M, Willett W, Hennekens $\mathrm{CH}$. Moderate alcohol intake, increased levels of highdensity lipoprotein and its subfractions, and decreased risk of myocardial infarction. N Engl J Med. 1993;329:1829-34.

4. Rubin R. Effect of ethanol on platelet function. Alcohol Clin Exp Res. 1999; 23:1114-8.

5. Marumo M, Wakabayashi I. Sensitivity of thrombin-induced platelet aggregation to inhibition by ethanol. Clin Chim Acta. 2009;402:156-9.

6. Salem RO, Laposata M. Effects of alcohol on hemostasis. Am J Clin Pathol 2005:123 Suppl:S96-105.

7. Barceloux DG, Bond GR, Krenzelok EP, Cooper H, Vale JA. American Academy of Clinical Toxicology ad hoc committee on the treatment guidelines for methanol poisoning. American Academy of Clinical Toxicology practice guidelines on the treatment of methanol poisoning. J Toxicol Clin Toxicol. 2002;40:415-46.

8. Phang PT, Passerini L, Mielke B, Berendt R, King EG. Brain hemorrhage associated with methanol poisoning. Crit Care Med. 1988;16:137-40.

9. $\quad$ Siess W. Molecular mechanisms of platelet activation. Physiol Rev. 1989;69: $58-178$

10. Marumo M, Wakabayashi I. Diverse effects of ethanol on $\mathrm{Ca}^{2+}$ entry and subsequent aggregation of platelets. Alcohol. 2010;44:343-50.

11. Grynkiewicz G, Poenie M, Tsien RY. A new generation of $\mathrm{Ca}^{2+}$ indicators with greatly improved fluorescence properties. J Biol Chem. 1985:260:3440-50.

12. Anonymous: Methanol institute. Methanol safe handling manual - health and safety module, 4th ed. 2017. http://www.methanol.org/wp-content/ uploads/2017/04/SafeHandlingManual-Health-Safety-Module.pdf.

13. Jarwani BS, Motiani P, Divetia R, Thakkar G. Rare combination of bilateral putaminal necrosis, optic neuritis, and polyneuropathy in a case of acute methanol intoxication among patients met with hooch tragedy in Gujarat. India J Emerg Trauma Shock. 2012;5:356-9.

14. Ferrari LA, Arado MG, Nardo CA, Giannuzzi L. Post-mortem analysis of formic acid disposition in acute methanol intoxication. Forensic Sci Int. 2003;133: 152-8.

15. Sakuma I, Arakawa M, Hirose Y, Sekiguchi H, Takayama M, Fujisawa M, Hori Y. Two cases of methanol poisoning with chronological measurements of blood concentrations of methanol, ethanol and formate. Chudoku Kenkyu (Jpn J Clin Toxicol). 2010;23:232-7. (in Japanese)

16. Morikawa G, Okazawa K, Shimizu T, Otagiri S, Fuwa F, Nakagawa S, Yamato S. Study of blood concentration analysis for formate in acute methanol poisoning. Chudoku Kenkyu (Jpn J Clin Toxicol). 2015;28:243-6. (in Japanese)

17. Yuan JP, Zeng W, Huang GN, Worley PF, Muallem S. STIM1 heteromultimerizes TRPC channels to determine their function as storeoperated channels. Nat Cell Biol. 2007;9:636-45.

18. Hofmann T, Obukhov AG, Schaefer M, Harteneck C, Gudermann T, Schultz G. Direct activation of human TRPC6 and TRPC3 channels by diacylglycerol. Nature. 1999;397:259-63.

19. Okada T, Inoue R, Yamazaki K, Maeda A, Kurosaki T, Yamakuni T, Tanaka I, Shimizu S, Ikenaka K, Imoto K, Mori Y. Molecular and functional characterization of a novel mouse transient receptor potential protein homologue TRP7. $\mathrm{Ca}^{2+}$-permeable cation channel that is constitutively activated and enhanced by stimulation of $\mathrm{G}$ protein-coupled receptor. J Biol Chem. 1999;274:27359-70

20. Marumo M, Suehiro A, Kakishita E, Groschner K, Wakabayashi I. Extracellular $\mathrm{pH}$ affects platelet aggregation associated with modulation of storeoperated $\mathrm{Ca}^{2+}$ entry. Thromb Res. 2001;104:353-60.

21. McMartin KE, Ambre JJ, Tephly TR. Methanol poisoning in human subjects. Role for formic acid accumulation in the metabolic acidosis. Am J Med. 1980;68:414-8.

\section{Submit your next manuscript to BioMed Central and we will help you at every step:}

- We accept pre-submission inquiries

- Our selector tool helps you to find the most relevant journal

- We provide round the clock customer support

- Convenient online submission

- Thorough peer review

- Inclusion in PubMed and all major indexing services

- Maximum visibility for your research

Submit your manuscript at www.biomedcentral.com/submit
Biomed Central 